Portland State University

PDXScholar

$1-4-1982$

\title{
A Comparison of the Effects of Non-operant and Operant Carryover Techniques for ///
}

Michelle Ann Tremblay

Portland State University

Follow this and additional works at: https://pdxscholar.library.pdx.edu/open_access_etds

Part of the Speech Pathology and Audiology Commons

Let us know how access to this document benefits you.

\section{Recommended Citation}

Tremblay, Michelle Ann, "A Comparison of the Effects of Non-operant and Operant Carryover Techniques for /I/" (1982). Dissertations and Theses. Paper 3230.

https://doi.org/10.15760/etd.3222

This Thesis is brought to you for free and open access. It has been accepted for inclusion in Dissertations and Theses by an authorized administrator of PDXScholar. Please contact us if we can make this document more accessible: pdxscholar@pdx.edu. 
AN ABSTRACT OF THE THESIS OF Michelle Ann Tremblay for the Master of Science in Speech Communications, with an emphasis in Speech Pathology/ Audiology, presented January 29, 1982.

Title: A Comparison of the Effects of Non-Operant and Operant Carryover Techniques for $/ 1 /$.

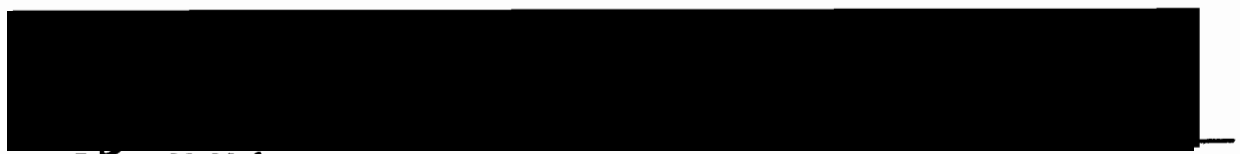

Joan McMahon

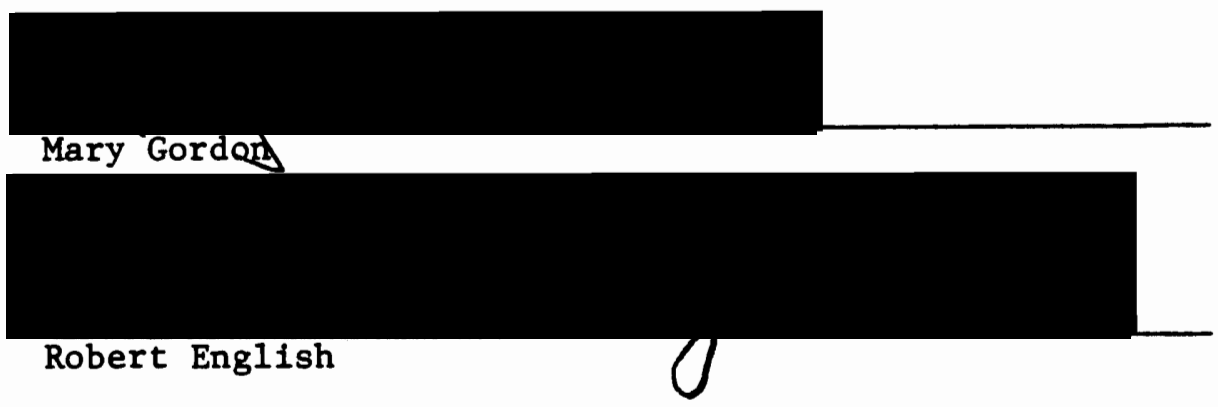

Developing strategies to promote effective carryover is one of the most difficult tasks a clinician faces. Mention has been made in the literature of possible activities to use in the clinical setting to promote carryover. Suggestion has been made in the literature that operant conditioning is a technique which can be employed to achieve carryover. The purpose of this investigation was to determine whether there is a difference in relative effectiveness between operant and non-operant techniques for achieving carryover of $/ 1 /$.

Six children enrolled in speech management for $/ 1 /$ in the 
Portland, Oregon metropolitan area and their clinicians were divided into two groups of three subjects each. The individual subjects comprising each group differed in several respects. Group I consisted of two males and one female, ages 10,10 and 5 years with a mean age of 8.3. The length of time in management ranged from four months to two years. Group II consisted of three males, ages 5, 6 and 9 years with a mean age of 6.7 years. The length of time in management ranged from five months to two years, four months. The subjects in Group I were administered a non-operant carryover program from their respective clinicians, with the exception of subject F. This subject essentially did not receive the operant program due to failure of meeting criterion for Step 1 and clinician 1llness. Each of the program's duration was five weeks. A pre- and post-test were administered by this investiagtor. Results from this study indicate that Group I, the non-operant group, regressed in articulatory proficiency of /1/ while Group II, the operant group, showed improvement. The percent of average change for Group I was -20.5, while Group II's percent of average change was 33.3 . Individual variables of the subjects and clinicians were considered for possible explanations of the differences found between the groups. Group I contained the oldest subjects, received training on fewer number of sounds than Group II and recelved more total minutes of speech management than Group II. Also, in comparison to the operant group, the cliniclans in the non-operant group had more years of experience in speech/language pathology in the public schools. The results of this study support the operant program's credibility in promoting carryover of $/ 1 /$ for this group of subjects. 


\section{A COMPARISON OF THE EFFECTS OF NON-OPERANT}

\section{AND OPERANT CARRYOVER TECHNIQUES FOR/I/}

$$
\text { by }
$$

MICHELLE ANN TREMBLAY

A thesis submitted in partial fulfillment of the requirements for the degree of

\section{MASTER OF SCIENCE IN SPEECH COMMUNICATIONS with an emphasis in SPEECH PATHOLOGY/AUDIOLOGY}

Portland State University 
TO THE OFFICE OF GRADUATE STUDIES AND RESEARCH:

The members of the Committee approve the thesis of Michelle Ann Tremblay presented January 4, 1982.

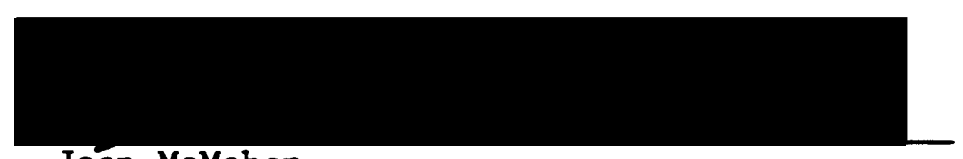

Joan McMahon
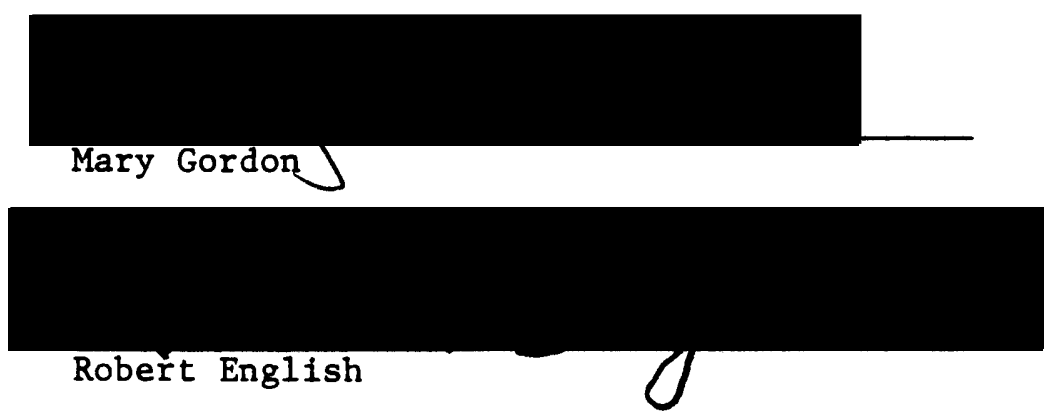

APPROVED :

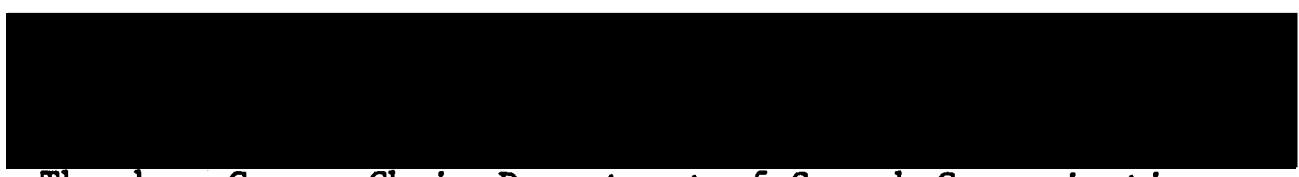

Theodore Grove, Chair, Department of Speech Communication

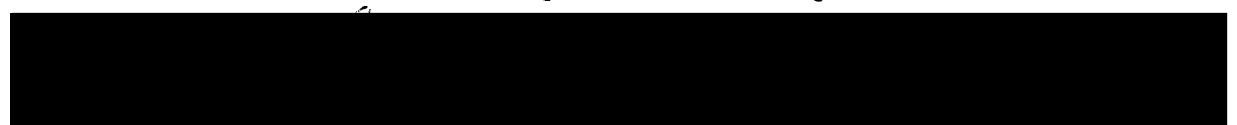

Stanłey E. Rauch, Dean of Graduate Studies and Research 


\section{ACKNOWLEDGEMENTS}

This work is dedicated to

Mom and Dad, Renee, Yvonne and Damian, Ron, Suzanne and Monique; my family, whose love encouragement and faith in me helped to make finishing graduate school a reality;

and to

Mark, my fiance and friend, who waited so patiently for me to finish school and whose sense of humor provided endless smiles through longdistance phone calls, letters and vacations together;

and a special dedication to

my support system these past two years: Mel, Jackie, Doug, Kathy, Jeanne, Jennie, Della and Vivian.

A last but not least note of appreciation goes to my adviser, supervisor, thesis director, and friend, Joan. 
TABLE OF CONTENTS

PAGE

ACKNOWLEDGEMENTS . . . . . . . . . . . . . . . . . . . . . . 1 . . . .

LIST OF TABLES . • . . . . . . . . . . . . . . . . • . . • vi

LIST OF FIGURES • . . . . . . . . . . . . . . . . . . . • vii

CHAPTER

I INTRODUCTION AND PURPOSE . . . . . . . . . . . . . . . 1

Introduction

Statement of Purpose

Definition of Terms

II REVIEW OF THE LITERATURE . . . . . . . . . . . . . . 4

Traditional or Non-Operant Methods

Operant Methods

Conclusion

III METHODS AND PROCEDURES . . . . . . . . . . . . . . 12

Methods

Subjects

Instrumentation

Procedures

Selection of Subjects

Pre- and Post-Testing

Carryover Programs

Analysis of Data

IV RESULTS AND DISCUSSION . . . . . . . . . . . . . . . 17

Results

Discussion

$\mathrm{V}$ SUMMARY AND IMPLICATIONS . . . . . . . . . . . . . 28

Summary

Implications

Research Implications

Clinical Implications 
BIBLIOGRAPHY . . . . . . . . . . . . . . . . . . . . . 32 APPENDIX
A PERMISSION FORM A • . . . . . . . . . . . . . . . . . 34
B PERMISSION FORM B . . . . . . . . . . . . . . . . 36
C PRE- AND POST-TEST . . . . . . . . . . . . . . . . 37
D CARRYOVER PROGRAM I . . . . . . . . . . . . . . . 39
E CARRYOVER PROGRAM II . . . . . . . . . . . . . . . . 41
F CLINICIAN QUESTIONNAIRE . . . . . . . . . . . . . . . 50
G CLIENT CASE HISTORY . . . . . . . . . . . . . . . . 51 


\section{LIST OF TABLES}

PAGE

TABLE

I Pre- and Post-test Results . . . . . . . . . . . 18 


\section{LIST OF FIGURES}

PAGE

\section{FIGURE}

1. Group I and II Carryover Profiles . . . . . . . . . . 20 
CHAPTER I

INTRODUCTION AND PURPOSE

\section{Introduction}

In addition to the acquisition of speech sounds, the speechlanguage clinician is equally, if not more, interested in the carryover of these sounds into the client's everyday speech. Ideally, the achievement of transferring an acquired skill into speaking situations outside the clinic is prerequisite to dismissal from the clinician's caseload. The client who achieves carryover will consistently use the correct sound in a11 speaking situations (Gerber, 1973). Thus, carryover is defined as the transfer of articulatory proficiency into spontaneous speech.

Developing strategies to promote effective carryover is one of the most difficult tasks a cliniclan faces (Sommers, 1969; Mowrer, 1971). Clinicians are well equipped to teach the production of a sound and subsequent use of that sound in limited contexts within the clinical setting. It is not guaranteed, however, that the client will utilize the target sound in his spontaneous speech outside of the clinic (Gerber, 1973).

Although mention has been made in the 11terature of possible inclinic and out-of-clinic activities to promote carryover (Backus and Beasley, 1951; Engel, Grandriet, Erickson, Gronhovd and Gunderson, 1966; Gerber, 1973), there has been 1ittle research undertaken to determine 
the effectiveness of these traditional carryover suggestions.

Within the last twenty years, it has become increasingly apparent that operant conditioning can be advantageously applied to speech and language management (Mowrer, 1973). A carefully planned intervention program is initiated by manipulating consequent events of a specific target behavior. Progress is continuously recorded and monitored by use of charts and graphs. Thus, the clinician can judge the outcome of intervention by the behavioral changes which have taken place (Mowrer, 1973).

Studies reported in the 1iterature have indicated correct sound production could be transferred into spontaneous speech. Carrier (1970) and Shelton, Johnson and Arndt (1972) found successful carryover results when trained parents used operant techniques with their children. Raymore and McLean (1972) in a study utilizing operant carryover principles with mentally retarded individuals essentially found results similar to those of Carrier (1970) and Shelton et al. (1972).

It is suggested in the 1iterature (Brookshire, 1967; McLean, 1970; and Mowrer, 1971) that operant conditioning is an effective technique which can be employed by various trainers to achieve carryover. Sufficient research comparing operant with other carryover techniques is lacking in the literature.

\section{Statement of Purpose}

This investigation was designed to assess operant and non-operant strategies utilized to promote the carryover of $/ 1 /$ in the public school setting. The question which this study sought to answer was: Is there 
a difference in the effectiveness of non-operant and operant management strategies to achieve carryover of $/ 1 /$ ?

\section{Definition of Terms}

For the purposes of this study, the following operational definitions were utilized.

\section{Carryover}

The transfer of articulatory proficiency into spontaneous speech outside the clinical environment without the presence of the clinician or clinically related stimulus materials.

\section{Operant Management}

A systematic framework of management techniques based on laboratory research in which shaping of desired responses are utilized, objectives are criterion referenced prior to inftiation and systematic use of stimulus control procedures are implemented.

\section{Traditional Management}

A variety of intervention techniques, strategies and activities not programmed along operant lines, i.e., stimulus-response-contingency. 
CHAPTER II

REVIEW OF THE LITERATURE

The child who correctly produces a target sound in the clinical setting and then leaves only to misproduce that sound in conversation with a friend on the playground has not achieved carryover. The sound is not in the repertoire of his everyday speech which is generally prerequisite to dismissal from speech management. The achievement of carryover is necessary before any teaching can be considered successful (Gerber, 1973).

How to effectively transfer the newly acquired sound from the clinic to everyday speaking situations is a problem of significant concern to most speech-language clinicians. Few techniques have been developed for successfully achieving carryover, and it is overlooked by many authorities in their writings (Sommers, 1969). It is not a new problem, as the Iiterature indicates, but is yet an unresolved issue in the field of speech-language pathology.

Carryover requires a certain amount of time and considerable planning to incorporate it into the management program so that target sounds are indeed used in conversational speech (Weiss, Lillywhite and Gordon, 1980). In-clinic and out-of-clinic activities are recommended in the literature. Gerbers' (1975) carryover program focused on practice of the target sound first in nonsense syllables, then in meaningful material. She also advocated quick and effortless production 
for automatic articulation. Parents and teachers assist in this program by monitoring the child's speech outside of the clinic. The child progresses in the program to more difficult levels when he has successfully completed a step.

Another critical factor for the success of carryover is auditory discrimination. The child needs to detect correct and incorrect sound productions both in his own speech and in others in order to use correct articulation spontaneously (Van Riper, 1978).

Dismissal of a client from a speech-language clinician's caseload indicates he has achleved carryover. This means the client uses his previously distorted sound automatically and consistently in spontaneous speech outside of the clinic. Determining when a client has attained articulatory proficiency is not easy as there are no universal procedures available for evaluating carryover (Weiss et al., 1980) and sometimes a client who has not achieved carryover will be dismissed from speech management. Wintz (1975) recommends tracking the client's conversational speech in and out of the clinic. The percentage of correct productions is used to monitor progress of carryover. Other means of evaluation include training parents, siblings, teachers and classmates to accurately evaluate the client's speech and to report the results to the clinician (Weiss et al., 1980). More research in carryover evaluation is needed in this area to further a clinician's competence in dismissing clients from their caseloads as corrected. The terms transfer, generalization and carryover are used interchangeably in the literature (Costello and Bosler, 1976; Griffiths and Craighead, 1972; McLean, 1976; Mowrer, 1971; Wing and Heimgartner, 1973). 
As previously defined, the term carryover will be utilized to mean the transfer of articulatory proficiency into spontaneous speech outside the clinical environment without the presence of the clinician or clinicallyrelated stimulus materials. Two techniques presently being employed by speech-language cliniclans to achieve carryover are traditional or nonoperant methods and operant methods.

\section{Traditional or Non-Operant Methods}

Traditional methods utilize a variety of intervention techniques and activities in an unprogrammed manner to correct deficient speech. The clinician is provided with guidelines with which to accomplish corrected speech. Van Riper (1978) suggested such methods as accompanying the child outside the clinic room, using the new sound in all types of speaking and emphasizing articulatory placement and movement rather than auditory feedback to automatize the corrective process of speech. Suggestions are given to aid the clinician in accomplishing these tasks such as giving the client assignments to use the sound in his environment, having him use a card to mark sound errors, using negative practice and other similar activities. The clinician's intuition is used as a guide In determining when the client has mastered a task and is ready to move on to a more difficult task.

Backus and Beasley (1951) advocated the use of group conversational situations to attain carryover. They contended this particular approach achieves permanence in the child's everyday speech because it facilitates the learning of new skills in real-life situations.

Other traditional techniques similar to the Backus and Beasley 
approach are creative dramatics and role-playing. In these techniques, children act out different situations where they would use their newly learned speech. The client is first instructed on how to produce the sound, then he is to use it in different contests and natural situations (Bush, 1978).

In addition to developing the sound in the clinical setting to insure carryover, many clinicians will employ persons in the child's environment. These people are the stimulus the child needs to evoke the correct sound (Mowrer, 1971). "Speech pals," usually friends and classmates, provide moral support to the speech-deficient child by spending fifteen minutes a day practicing his "good speech sound" (Marquardt, 1959). Parents and teachers also provide the needed reminder for the child to use his good speech (Carrier, 1970; Wing and Heimgartner, 1973).

Engel et al. (1966) provide a wealth of carryover activities and suggestions which involve people in the child's environment and the child himself. Suggestions are given for activities in the clinical setting and outside the clinical environment.

Homework is an important traditional ingredient to achieving carryover. In an effort to require the child to use his "new speech" outside the clinic, he may be assigned to ask his teacher a question that includes the sound he is learning. Speech notebooks are taken home by the clients in an effort to help them remember to use their target sound at home. A note also may be hung on the client's bedroom door or other conspicuous place as a reminder. At an unspecified time in management parents and teachers are requested to start working with 
the client at home and at school (Weiss et al. 1980).

Traditional management applied to carryover includes stabilizing and automatizing the new sound by having the child engage in selfexpressive types of speaking situations at different emotional levels (Van Riper, 1978). The process is random, however, as the clinician chooses people in the child's environment to help aid carryover and makes relevant assignments for the cllent to use the target sound more often outside of the clinic. The clinician is the one who decides when the child has mastered the new sound in spontaneous speech.

\section{Operant Methods}

Operant conditioning has been advantageously applied to the field of speech-language pathology within the past twenty years (Mowrer, 1973). To the operant clinictan, speech is learned behavior and articulatory proficiency can be accelerated by the manipulation of specified environmental and social events (Mowrer, Baker and Schultz, 1978). Operant conditioning possesses certain characteristics (stimulus-response-contingency) which make it a relevant technique in the field of speech-language pathology (Brookshire, 1967). The 1iterature supports the use of operant principles both in acquisition of the speech sounds and in carryover.

Brookshire (1967) defines operant conditioning as a process whereby consequences or consequent events are presented contingent upon a response so that the rate of the response is controlled. Thus, the result is an increase or decrease in the response, dependent upon the contingencies. The goal of an operant training program is to produce 
high rates of correct responses and to decrease incorrect responses; progress is continually recorded and monitored by use of charts and graphs. The outcome of intervention is judged by the behavioral changes which have occurred (Mowrer, 1973).

Carrier (1970) utilized operant methods (stimulus-responsecontingency) based on the principle of stimulus-shift which is changing the stimulus while the response remains the same. For example, a child having learned how to produce a target phoneme in one setting is required to produce it in a different setting. Thus, the response is the same but the stimulus that evokes it is different. They reported improvement in their children's speech and that correct articulation was generalizing into conversational speech.

Costello and Bosler (1976) conducted a study utilizing Carrier's (1970) articulation program. Again, mothers provided management in their homes. Periodically, during management, each child was taken to the clinic to test for generalization of the correct articulation learned in the home. Results showed correct articulation was carried over into another setting other than the one where the training occurred.

A similar study employed both parents in automating articulatory responses of their children (Shelton, Johnson and Arndt, 1972). The parents monitored and reinforced correct production of /s/ phonemes. A four month post-test indicated that gains made during the program were maintained.

Operant training was utilized by Wheeler and Sulzer (1970) to establish a particular verbal response in a speech-deficient child. 
The results indicated that the verbal response generalized to untrained and novel stimuli, although it occurred at a lower level of accuracy than in the training situation. The authors attributed the positive results to the training procedures which consisted of chaining, tracking and differential reinforcement.

Wing and Heimgartner (1973) developed a carryover program which was implemented by parents and found to be effective. Five oral reading hierarchies were devised through which the child progressed. Criterion for movement from step to step was 100 percent accuracy for three consecutive practice sessions on at least three different days. The success of this program was assumed to be due to the clearly defined home assignments, frequent intervals of practice, daily recording of results and realistic goals specified.

Thus, behavior does appear to carryover into settings outside of the training setting. The results of the studies related in the literature utilizing operant conditioning in modifying speech and language behavior holds a strong promise of a soundly based method effective in articulation carryover.

\section{Conclusion}

It is not surprising that, because carryover is not easily achieved and because it is of vital importance to management, there are a variety of techniques and published programs available to aid the clinician. Even with this wealth of information, speech-language clinicians still complain that carryover is the most difficult phase of management (Sommers, 1969). It is frustrating to clinicians when the 
corrected sound is inconsistently used, if at all, in everyday speech (Gerber, 1973).

The literature indicates the need for further research of both traditional and operant management techniques applied to carryover. The lack of data supporting the efficacy of traditional techniques may be the reason why so many clinicians using these procedures are frustrated with the lack of carryover their clients achieve. Operant methods have been shown to be successful; however, the process by which this occurs is not conclusive. Operant procedures have been investigated but have not been compared with traditional techniques and traditional techniques have not been evaluated at all. This study, therefore, seeks to compare the two types of approaches, nonoperant and operant, in an effort to determine whether there is a difference in relative effectiveness between them for attaining articulation carryover. 


\section{CHAPTER III}

\section{METHODS AND PROCEDURES}

\section{Methods}

\section{Subjects}

Subjects for this study consisted of six public school children enrolled in speech management and scheduled for at least two times per week in the Portland, Oregon metropolitan area school districts. The ages of the subjects ranged from five to ten years with a mean age of 7.5. These subjects met the following requirements: 1) normal hearing bilaterally as determined by an audiometric screening at $20 \mathrm{~dB}$ HL for the frequencies $500,1,000$ and $2,000 \mathrm{~Hz} \cdot$; and 2) correct /1/ production in the clinical setting but not in spontaneous speech outside of the clinical setting as per their speech clinician's report.

Six speech clinicians employed in the Portland, Oregon, metropolitan area also participated in this study by providing speech services to their respective clients (the subjects of this study) for remediation of $/ 1 /$. Their years of experience as speech-language clinicians in the public schools ranged from one year to twenty years with a mean of 16 years. Criteria for clinician participation in this study included: 1) more than nine months experience in the public school setting as a speech-language cliniclan; and 2) a caseload containing a child who produced /1/ in the clinical setting, but not 
consistently in spontaneous speech.

A consent form was signed by the clinician as well as by the parents of the subject. (Appendices A and B). The subjects were divided Into two groups, I and II, of three subjects each. Group I received traditional or non-operant methods to promote carryover of /1/. Group II recelved operant methods to promote /I/ carryover. The individual subjects comprising each group differed in several respects. Group I consisted of two males and one female, ages 10, 10 and 5 years with a mean age of 8.3. The length of time in management ranged from four months to two years. Group II consisted of three males, ages 5, 6 and 9 years with a mean age of 6.7 years. The length of time in management ranged from five months to two years, four months.

\section{Instrumentation}

The audiometer utilized for the hearing screening was a portable Beltone 15 C. A Soni Matic reel-to-reel tape recorder, Model TC-104 A, was utilized by this investigator for the purpose of recording the pre- and post-test conversation of each subject participating in this study. A response form was designed to track the subjects' correct and incorrect $/ 1 /$ productions during the pre- and post-test (Appendix C).

\section{Procedures}

\section{Selection of Subjects}

This investigator located clinicians willing to participate in this study by means of either a telephone call or a questionnaire 
which was distributed at the Oregon Speech and Hearing Association Conventions in October, 1980 and in Spring, 1981. The clinicians were asked whether they had an /1/ client in their caseload who was at the carryover phase of management. If so, they were then asked if they would be willing to perform a five week carryover program with that client. The clients of the six clinicians who consented to participate were randomly assigned to Group I or Group II. The hearing screening was conducted by each subject's speech-language clinician.

Pre- and Post-Testing

The pre- and post-test were administered at the subject's respective schools in a location other than the speech room. Each subject was tested by this examiner, who posed as an individual in need of their help in defining some words for a dictionary she was making. This was essential for obtaining a spontaneous speech sample outside of the clinical setting without the subject being conscious of producing / $/ /$ correctly. This investigator asked the subject to define a list of twenty-five words, ten of which easily elicited $/ 1 /$. The remaining fifteen words were used as foils. A random order table was utilized to determine the order in which the words were presented. Each of the subject's /1/ productions were recorded on a plus/minus basis as correct or incorrect by this investigator on the recording sheet which was out of view from the subject's observation. The preand post-test sessions also were recorded on audio-tape.

\section{Carryover Programs}

Following the pre- and post-testing, the clinicians were provided 
with the non-operant carryover program (Appendix D) or the operant carryover program (Appendix E). The non-operant program consisted of six activities which involved the client using /1/ outside of the clinic by himself and with others such as friends, parents, teachers and other school personnel. The clinician was instructed to assign all the activities to the client. The duration and sequence of activities was left up to clinician discretion. The operant program consisted of a hierarchy of twelve criterion referenced steps in which the client used $/ 1 /$ outside of the clinic. The clinician, teachers, other school personnel and the child himself were involved in tracking correct $/ 1 /$ production. The subject did not move to another step until criterion was met. If a step failed to be mastered a branch step was administered which was similar to the one failed but easier. This examiner met with each of them individually to provide instructions and answer any questions. The clinicians then administered the five week carryover program to their clients.

A post-test was obtained by this investigator exactly five weeks following the pre-test. This was obtained in the same manner as was the pre-test.

Individual subject and clinician variables which might influence the results of this study were obtained by two questionnaires which were completed by each of the clinicians (Appendices $F$ and $G$ ).

\section{Analysis of Data}

The first $20 / 1 /$ productions of each subject were used for descriptive comparison. The percentage of correct responses for each 
pre- and post-test measurement was computed. A comparison was then made between the two carryover programs using the changes in the preand post-test measures. These changes were determined by dividing the increase or decrease of correct responses by the total possible number of increases. 
CHAPTER IV

RESULTS AND DISCUSSION

\section{$\underline{\text { Results }}$}

The purpose of this investigation was to determine whether there is a difference in relative effectiveness between operant and nonoperant techniques for achieving carryover of $/ 1 /$. Group $I$, composed of three subjects, received a non-operant carryover program for $/ 1 /$. Group II, also composed of three subjects, received an operant carryover program for the same phoneme with the exception of subject F. Subject $F$ essentially did not receive the operant carryover program due to failure of meeting criterion for step 1 and clinician illness. Results were obtained by comparing the scores of change by dividing the increase of correct responses by the total possible increase.

Pre- and post-test results and percentage of change for the subjects who participated in the carryover programs are shown in Table I. The results show there was no improvement in carrying /1/ over into spontaneous speech for any member of Group I. The three subjects in this non-operant group displayed regressions of $-5.8,-30$, and -50 percent in correct production with a mean regression of -20.6 percent. For Group II the results indicate a mean improvement of 33.3 percent with two of the subjects in this operant group, $D$ and $E$, Improving 25 and 80 percent respectively. The third subject, $F$ who 


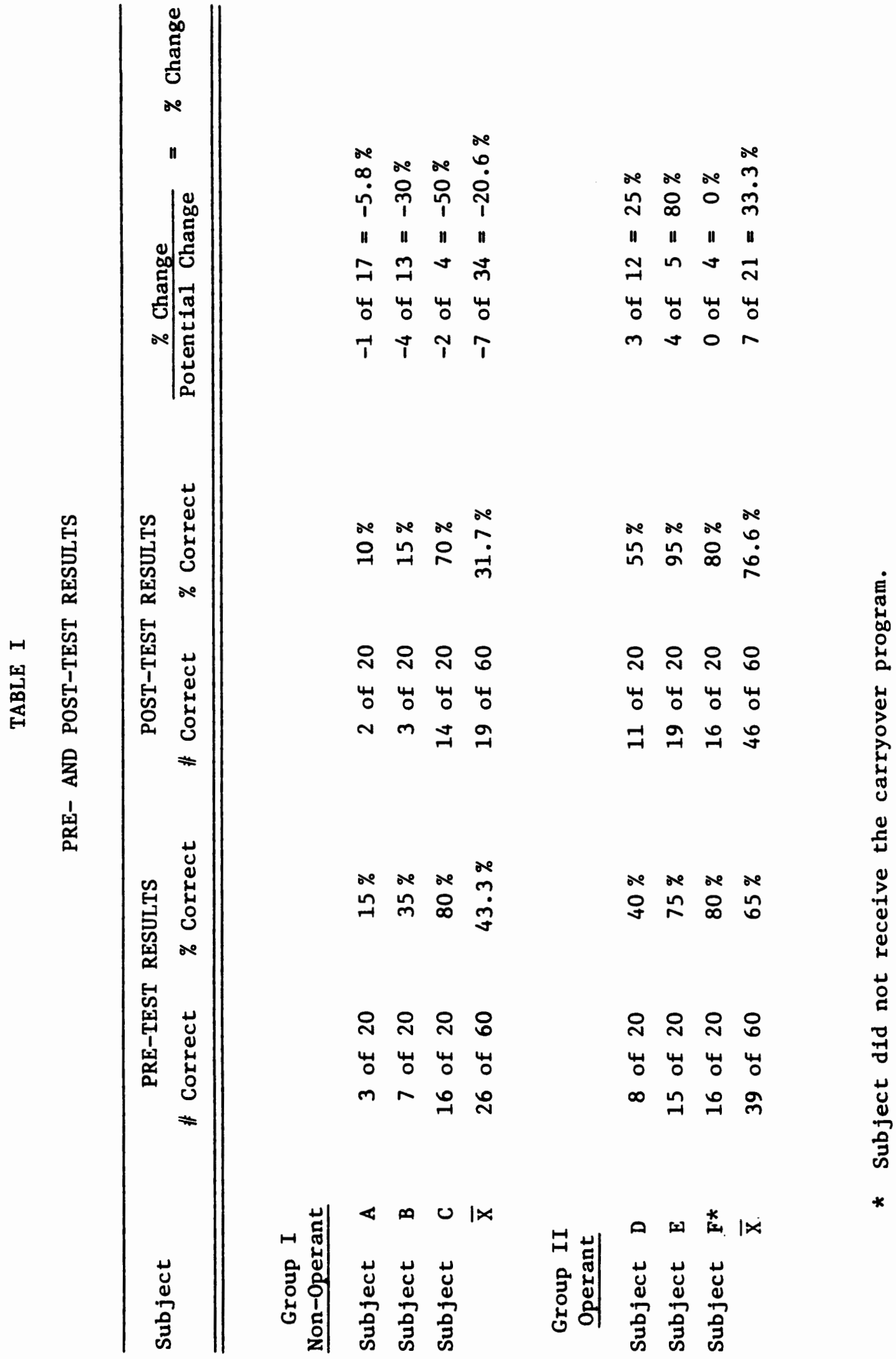


did not receive Carryover Program II, did not show improvement or regression, due to the reasons stated above.

The results of this study indicated a difference in relative effectiveness between the two carryover programs. Pre- and post-test profiles of the subjects in both groups are illustrated in Figure 1. The operant group showed improvement in articulatory proficiency of /1/ with a change score of 33.3 percent. The non-operant group, with a change score of -20.6 , did not improve in attaining proficiency of /1/. Some basic differences existed between the two groups and these will be discussed below.

\section{$\underline{\text { Discussion }}$}

Pre-test results show that Group I (non-operant) began with a lower percentage of correct / / / productions than Group II (operant). This indicates a disadvantage for Group I in attaining carryover since Group II was essentially more proficient at using / $/$ / in conversational speech outside of the clinic by 21.7 percent.

The average age of the subjects in Group I, the non-operant group, was 8.3, while the average subject age of Group II, the operant group, was 6.7 years. This shows there was almost two years difference in mean ages between groups. Group I, having the older subjects, did not do as well in spontaneous $/ 1 /$ production as Group II. This poor performance by the older subjects is inconsistent since maturation should aid the mastery of learning to produce sounds. These results, however, may indicate the older group had disordered articulation while the younger group may have had delayed speech. 


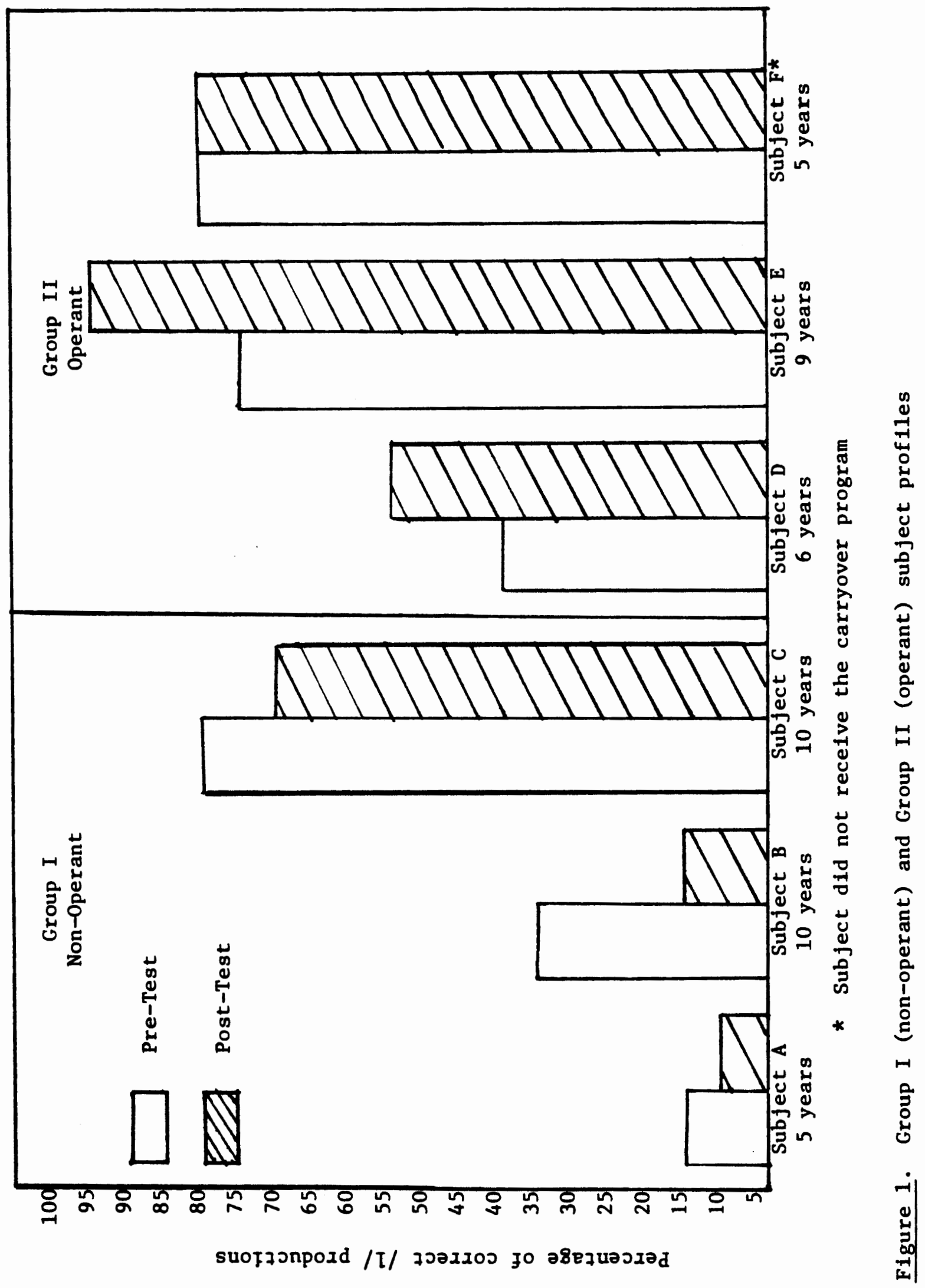


That is, the habit strength for misproducing /1/ may have been stronger in the older group which could explain the older group's poor performance.

The average number of sounds each client had been working on since his initial placement in the speech program was 1.6 for Group I and 2.3 phonemes for Group II. Group II may have generalized /1/ outside of the clinic with more proficiency than Group I because they had more practice with learning more sounds.

Length of time in speech was another variable for comparison of the groups. The non-operant group was in speech for an average of two times per week for 18.3 minutes each session and 1.03 years. The operant group was also in speech on the average of two times per week, but for only 14 minutes each session and for 1.1 years. The operant group had 4.3 fewer minutes of instruction than the non-operant group. These results indicate essentially no difference in length of time between groups so it was probably not a factor contributing to the difference in group performance.

The clinicians in each group also showed variables which may have been important in the differences shown by the two carryover groups. For instance, the average years of experience as a speech/language clinician in the public schools for the non-operant group was 13.6 , while the operant group had 2.3 years of average experience. Those subjects whose cliniclans had less experience in the field achieved more proficiency in using /I/ outside of the clinic, while the subjects in the non-operant group whose clinicians had more experience did not improve. A possible explanation for this is that training may 
have differed between those who had more experience and those with less experience. This may have had an influence on the success of progress in carryover. That is, new techniques may have focused more attention on carryover programs and operant technology than in the past.

The number of schools the clinicians were serving did not seem to be an important factor in accounting for variations between the groups. In both groups, the average number of schools the clinicians were serving was 2.3 and the average size of caseload was 37.3 children.

Each of the clinicians were assigned a carryover program, nonoperant or operant, at random. The particular type of management they used prior to the carryover program could have a bearing on how effective carryover was as consistency in the flow of a client's program is very possibly conductive to improvement. Only one clinician in Group I, the non-operant group, also used a non-operant approach to learning $/ 1 /$ in the clinic. Her client showed regression in $/ 1 /$ carryover by 5.8 percent. The other two clinicians in this group used an operant approach prior to carryover. Their clients also showed regression of 30 and 50 percent, however, in carryover of $/ 1 /$. These approaches will be described later. In contrast to this, all three clinicians in Group II, the operant group, also used an operant approach prior to initiating carryover. This consistency in approaches for Group II could have been an advantage as the subjects were conditioned for operant procedures and there was no change in format and instruction from in-clinic to outside of clinic activities. Individual variables of the subjects themselves also likely contributed to the overall results between groups. The variables 
which are discussed below were reported by each of the subject's clinicians.

Subject $A$ of the non-operant group was five years old and a kindergartner. She liked to come to speech class and was motivated to change her speech. Her classroom teacher reported her to be a "slow learner," but she was well-adjusted in school and at home. The only sound on which she was working was /1/ two times per week for 15 minutes and for a period of four months. Her clinician used a nonoperant approach to teaching / $/ /$ production in clinic. This consisted of teaching the sound in isolation, in syllables, words, sentences and conversation with no data collection, response tracking or criteria for moving from one step to the next. The clinician imposed responsibility on subject $A$ for her own program by having her selfmonitor her own and the clinician's / / productions in clinic. This subject regressed in articulatory proficiency from inside the clinical setting to spontaneous speech outside of the clinic by 5.8 percent. Compared to the others in her group, however, subject A showed the least amount of regression. The possibility that this subject may have been a slow learner and the fact she was not responsible for use of $/ 1 /$ outside of the clinical setting may have been contributing factors of her regression in achieving carryover.

Subject $B$ of the non-operant group was 10 years old and a fourth grader. His clinician reported he had a few problems with the rules of school, but they were usually the result of boredom as he was a bright student and not always challenged. Improving his speech also was not a high priority in his life. He had been working on the /r/ 
and $/ 1 /$ phonemes in clinic simultaneously and successfully corrected $/ \mathrm{r} /$ before $/ 1 /$. He attended speech sessions two times per week for 15 minutes and for a perfod of one and one-half years. The approach his clinician used prior to carryover was a published behavioral program entitled /1/ AMP (Articulatory Modification Program) by Collins, Cunningham and Bakke (1976). The criteria for movement from step to step was 20 out of 25 responses correct. The responsibility imposed on the subject by his clinician was to complete experiences and assignments outside of the clinic such as selecting/1/ words in his school lessons and then reporting about them to his clinician. This subject was not motivated to improve his speech and perhaps going from a very structured program (/1/ AMP) to a less structured carryover program (non-operant) was a possible reason for his regression in spontaneous /1/ production of 30 percent.

Subject $C$ of the non-operant group, was also 10 years old and in the fourth grade. His clinician reported a few classroom behavioral problems, although he enjoyed coming to speech and wanted to improve his production of $/ 1 /$. While in speech for a period of two years he worked on $/ \theta /$ and $/ 1 /$ two times a week for 25 minutes a session. His clinician used two behavioral programs, the /1/ AMP and selected portions of the Universal Articulation Program (Brown, Timm and Evans, 1972) prior to infitiating the non-operant carryover program. Similar results can be concluded of subject $C$ as with subject $B$ in that transition from an operant program in clinic to a non-operant carryover program outside of clinic may not have been sufficient structure for these subjects to successfully use /1/ in conversational 
speech. Subject $C$ showed a regression in percent of change from preto post-test of 50 percent. He also did not have any responsibility for using / / outside of the clinical setting which may not foster carryover. Any of these individual subject variables of this nonoperant group may be possible reasons for the regression in articulatory proficiency of $/ 1 /$.

Operant Group II, on the average, showed Improvement in using /1/ in conversational speech by 35 percent. Subject D was six years old and in the first grade. His clinician reported him to be a very reticent and nervous child which possibly interfered with his school work and potential of learning. His only deviant sound was $/ 1 /$ on which he worked for a period of five months, two times per week for approximately seven minutes per session as he was in a group of four and was the only one working on $/ 1 /$. This factor is significant as he received the least amount of instruction time compared to the others in both groups and improved in use of /1/ in spontaneous speech by 25 percent. It also is significant to note that this subject did not successfully complete step 1 of carryover program II but repeated it three times with the branch steps in between. The clinician reported he became nervous when she walked into the classroom to track his / $/$ / productions. A possible reason for subject $D^{\prime}$ s improvement is that his clinician utilized an operant approach prior to carryover using occasional tracking of 90 percent criterion for movement from one step to the next.

Subject $E$ of the operant group was nine years old and in the fourth grade. He had no home or school problems. He liked coming to 
speech and wanted to improve his production of sounds he distorted but, as reported by his clinician, did not always take responsibility for his speech. It appears, however, that this subject was required to do many activities which represented self-responsibility. He used /1/ outside of clinic with parents and teachers, and self-tracked his own /1/ productions with a mirror, a language master, tape recorder, and video tape. He also had "speech friends" help him remember to use correct / / outside of clinic. This subject's history shows he has worked on phonemes $/ \theta, s, r, 1$, and $z /$ and has been in speech for two years, four months, the longest of all subjects. His previous management was operant as his clinician utilized the /1/ AMP and also incorporated parents and teachers into the program who tracked /1/ productions after each step of the program was completed. It is this investigator's belief that the consistent use of operant procedures throughout subject E's program was an advantage to his improvement of /1/ proficiency outside of clinic by 80 percent. In addition to this, it is significant to note that subject E completed carryover Program II in its entirety without having to repeat any steps.

The last subject in the operant carryover program, subject $F$, was five years old and in kindergarten. He liked his speech classes and seemed to want to improve his speech. He was working on two sounds: the $/ \mathrm{r} /$ and $/ 1 /$. He spent six months in clinic before carryover and progressed through an operant program during this time. His clinician utilized the Universal Articulation Program but modified the criterion level for moving from step to step to 90 percent accuracy. No responsibility was placed on this subject for his own program. 
Subject $F$ did not improve or regress with the use of carryover Program II and so achieved a change score of 0 percent. A possible reason for this is that step 1 of the carryover program was not initiated until nine school days after the pre-testing as he had not achieved the required 90 percent accuracy in clinic. With successful completion of step 1, the clinician became 111 and was unable to complete the administration of this program. Thus, subject $F$ cannot be considered for discussion as he essentially did not participate in this study.

In conclusion, for these two carryover groups, the operant

program appeared to achieve the better results for carryover of /1/ into spontaneous speech outside of the clinical setting. It also appeared that the use of an operant carryover program prior to carryover was advantageous. The conclusions, however, are written cautiously as a larger sample of subjects would be more representative of the actual proficiency for these carryover programs. 


\section{CHAPTER V}

\section{SUMMARY AND IMPLICATIONS}

\section{Summary}

Developing strategies to promote effective carryover is one of the most difficult tasks a clinician faces (Sommers, 1969; Mowrer, 1971). Mention has been made in the literature of possible activities to use in the clinical setting to promote carryover (Backus and Beasley, 1951; Engel, Grandriet, Erickson, Gronhovd and Gunderson, 1966; Gerber, 1973). Few research studies, however, have been undertaken to determine effective techniques that actually achieve carryover. Suggestion has been made in the 1iterature (Brookshire, 1967; McLean, 1970; Mowrer, 1971) that operant conditioning is a technique which can be employed to achieve carryover. The purpose of this investigation was to determine whether there is a difference in relative effectiveness between operant and non-operant techniques for achieving carryover of $/ 1 /$.

Six children enrolled in speech management for $/ 1 /$ in the Portland, Oregon metropolitan area and their clinicians were divided into two groups of three subjects each. The individual subjects comprising each group differed in several respects. Group I consisted of two males and one female, ages 10,10 and 5 years with a mean age of 8.3. The length of time in management ranged from four months to two years. Group II consisted of three males, ages 5, 6 and 9 years 
with a mean age of 6.7 years. The length of time in management ranged from five months to two years, four months. The subjects in Group I were administered a non-operant carryover program from their respective clinicians. Group II received an operant carryover program from their respective clinicians, with the exception of subject $F$. This subject essentially did not receive the operant program due to failure of meeting criterion for Step 1 and clinician illness. Each of the program's duration was five weeks. A pre- and post-test were administered by this investigator.

Results from this study indicate that Group $I$, the non-operant group, regressed in articulatory proficiency of $/ 1 /$ while Group II, the operant group, showed improvement. The percent of average change for Group I was -20.5 , while Group II's percent of average change was 33.3 . Individual variables of the subjects and clinicians were considered for possible explanations of the differences found between the groups. Group I contained the oldest subjects, received training on fewer number of sounds than Group II and received more total minutes of speech management than Group II. Also, in comparison to the operant group, the clinicians in the non-operant group had more years of experience in speech/language pathology in the public schools. The results of this study support the operant program's credibility in promoting carryover of $/ 1 /$ for this group of subjects.

\section{Implications}

Research Implications

The results of this investigation are not conclusive due to the 
small number of subjects. Replication of this study using at least 20 subjects in each group would yield more conclusive results as to the efficacy of operant and non-operant carryover techniques.

Another possible area of research may be to use phonemes other than $/ 1 /$. This may determine if there is a difference in carryover into spontaneous speech for various phonemes.

A third area of possible study might be to control for management practices prior to the carryover phase of management. For instance, for a group who received non-operant management techniques prior to carryover, the investigator could provide an operant carryover program. For those receiving an operant regime prior to carryover, provide a non-operant carryover program. A study that provides a carryover program consistent with the type (non-operant or operant) of previous management the subject recelved also would yield interesting data for comparison.

Five weeks of carryover management may not be enough time to achieve good carryover or it may be more time than is necessary. A study which provides carryover for more or less than five weeks may obtain different results.

\section{Clinical Implications}

The results of this study indicate operant techniques may be advantageous in promoting carryover of $/ 1 /$. It also appears that employing an operant program both in the management and carryover stages may be beneficial to the transfer of correct sound production. Thus, clinicians who use operant strategies consistently may find their clients using their previously distorted sounds in spontaneous speech 
sooner than if non-operant techniques are used. 


\section{BIBLIOGRAPHY}

BACKUS, 0. and BEASLEY, J., Speech Therapy with Children. Cambridge, Massachusetts: The Riverside Press, 1951.

BROOKSHIRE, R. H., Speech pathology and the experimental analysis of behavior. JSHD 32 (3), 215-27, (1967).

BROWN, K., TIMM, K., and EVANS, E., Universal Articulation Modification Program. Boston, Massachusetts: Teaching Resources Corporation, 1972 .

BUSH, C. S., Creative drama and language experiences: Effective clinical techniques. LSHSS 9 (4), 254-8 (1978).

CARRIER, J. K., A program of articulation therapy administered by mothers. JSHD 35 (4), 344-53 (1970).

COLLINS, P., CUNNINGHAM, G., and BAKKE, S., /1/ AMP Articulation Modification Program. Gladstone, Oregon: C. C. Publications, 1976.

COSTELLO, J. and BOSLER, S., Generalization and articulation instruction. JSHD 41 (4), 359-73 (1976).

ENGEL, D., GRANDRIET, S., ERICKSON, K., GRONHOVD, K., and GUNDERSON, G., Carryover. JSHD 31 (3), 227-33 (1966).

GERBER, A., Goal: Carryover, An Articulation Manual and Program. Philadelphia: Temple University Press, 1973.

GRIFFITHS, H., and CRAIGHEAD, W. E., Generalization in operant speech therapy for misarticulations. JSHD 37 (4), 485-94 (1972).

MARQUARDT, R., Carryover with "speech pals." JHSD 24 (2), 154-7 (1959).

McLEAN, J., Articulation. In Lloyd, L. Communication Assessment and Intervention Strategies. Baltimore: University Park Press, 1976.

McLEAN, J. C., Extending stimulus control of phoneme articulation by operant techniques. In F. Girardeaq and J. Spradlin (Eds.), $\underline{A}$ Functional Analysis Approach to Speech and Language. ASHA Monogr. 14. Washington, D. C.: American Speech and Hearing Association, $24-47$ (1970).

MOWRER, D. E., A behavioral approach to modification of articulation. 
in W. D. Wolfe and D. J. Goulding (Eds.), Articulation and Learning. Springfield, Illinois: Charles C. Thomas, 1973.

MOWRER, D. E., Transfer of training in articulation therapy. JSHD 36 (4), 427-46 (1971).

MOWRER, D. E., BAKER, R. L., and SCHULTZ, R. E. Operant procedures in the control of speech articulation. In $H$. N. Sloane and B. D. MacAulay (Eds.), Operant Procedures in Remedial Speech and Language Disorders. Saint Louis: The C. V. Mosby Company, 1978.

RAYMORE, S, and MCLEAN, J. E., A clinical program for carryover of articulation therapy with retarded children. In J. E. McLean, D. E. Yoder and R. L. Schiefelbusch (Eds.), Language Intervention with the Retarded: Developing Strategies. Baltimore: University Park Press, 1972.

SHELTON, R. L., JOHNSON, A. F., and ARNDT, W. B., Monitoring and reinforcement by parents as a means of automating articulatory responses. Percept. Mot. Skills, 35, 759-67 (1972).

SLOANE, H. N., and MacAULAY, G. D., Operant Procedures in Remedial Speech and Language Training. Boston: Houghton Mifflin Company, 1968.

SOMMERS, R. K., The therapy program. In R. Van Hattum (Ed.), Clinical Speech in the Schools. Springfield, Illinois: Charles C. Thomas, 1969.

VAN RIPER, C., Speech Correction: Principles and Methods. New Jersey: Prentice Hall, 1978.

WEISS, C. E., LILLYWHITE, G. S., and GORDON, M. E., Clinical Management of Articulation Disorders. Saint Louis, Missouri: The C. V. Mosby Co., 1980.

WHEELER, A. J., and SULZER, B., Operant training and generalization of verbal response form in a speech deficient child. JABA 3 (2), 139-47 (1970).

WING, D. M., and HEIMGARTNER, L. M., Articulation carryover procedure implemented by parents. LSHSS 4 (4), 182-90 (1973).

WINTZ, H., From Syllable to Conversation. Baltimore: University Park Press, 1975. 


\section{APPENDIX A}

\section{PERMISSION FORM A}

I

agree to allow my child

to participate as a subject in the study

entitled "The Effects of Operant and Non-Operant Techniques on the Carryover of the / $1 /$ Sound." This study is carried out by Michelle Tremblay under the supervision of Joan McMahon, thesis director, Speech and Hearing Science Program, Portland State University.

The purpose of this study is to determine if there is a difference In relative effectiveness of two techniques, operant and non-operant, on the carryover of the $/ 1 /$ sound. My child, who has completed a training program which taught him/her to correctly say the $/ 1 /$ sound by his/her speech clinician, will take part in an activity with Michelle Tramblay which tests for the carryover of $/ 1 /$ in conversational speech. I understand this test consists of my child defining some words for Michelle Tremblay who is posing as an individual constructing a dictionary. I recognize it is essential that I not explain the dictionary activity to my child as it will not insure a true sample of my child's speech in conversation.

There are no risks or dangers inherent in the procedures of this study. All information will be kept confidential and the identity of my child will remain anonymous. I understand subjects are free to withdraw from the study at any time. 
Permission Form A

Page 2

Signature of Parent/Guardian

Date

Please return this form with your child to his/her speech clinician indicating your approval (or disapproval). If you have any questions, please feel free to call me in the evenings at 245-3648 (Michelle Tremblay). 


\section{APPENDIX B}

\section{PERMISSION FORM B}

I agree to participate in the study entitled "The Effects of Operant and Non-Operant Techniques on the Carryover of $/ 1 / . "$ This study is carried out by Michelle Tremblay under the supervision of Joan McMahon, thesis director, Portland State University .

The purpose of this study is to determine if there is a difference in relative effectiveness of two techniques, operant and non-operant, on the carryover of $/ 1 /$. I understand that I will provide an operant or non-operant carryover program to (client) for a period of 5 weeks to promote carryover of $/ 1 /$. There are no risks or dangers inherent in the procedures of this study. All information will be kept confidential and the identity of all subjects will remain anonymous. I understand I am free to withdraw from the study at any time. 
APPENDIX C

PRE- AND POST-TEST

\begin{tabular}{|c|c|c|}
\hline Stimulus Words & $\frac{\text { Pre-test }}{\text { (date) }}$ & $\frac{\text { Post-test }}{\text { (date) }}$ \\
\hline 1. rake & & \\
\hline 2. radio & & \\
\hline 3. key & & \\
\hline 4. snow & & \\
\hline 5. chimmey & & \\
\hline 6. rabbit's foot & & \\
\hline 7. cake & & \\
\hline 8. flashlight & & \\
\hline 9. joke & & \\
\hline 10. ring & & \\
\hline 11. car & & \\
\hline 12. washing machine & & \\
\hline 13. window & & \\
\hline 14. donut & & \\
\hline 15. eraser & & \\
\hline 16. coat & & \\
\hline 17. lemonade & & \\
\hline 18. sleep & & \\
\hline 19. elevator & & \\
\hline
\end{tabular}


Pre- and Post-Test

Page 2

\begin{tabular}{l|l|l} 
20. tiny & & \\
\hline 21. book & & \\
\hline 22. school & & \\
\hline $23 . \quad$ piano & & \\
\hline 24. camera & & \\
\hline $25 . \quad$ rainbow & & \\
\hline
\end{tabular}




\section{APPENDIX D}

\section{CARRYOVER PROGRAM I}

Instructions to the clinician:

This is a five week carryover program and includes the following activities. The activities take place outside of the clinic. You are to assign the activities to your client who is in the carryover phase of management for $/ 1 /$. The sequence and duration of the activities are left up to your discretion, however, all activities must be incorporated.

1. Have client put pictures or words containing the $/ 1 /$ sound in a notebook. Instruct him to practice the $/ 1 /$ sound by referring to the pictures and words and talking about them.

2. Send a note home to the client's parents asking them to begin working with their child on the /1/ sound. The parents should listen for good $/ 1 /$ sounds and reinforce them.

3. Instruct the client to put signs with pictures and words of the /1/ phoneme in a place where he will be reminded to produce his "good /1/ sound" (e.g. on his bedroom door, school desk, school notebook, etc.).

4. Ask any teachers the child has or is acquainted with and any other school personnel willing to help to listen for the client's correct production of $/ 1 /$. Have them reinforce good productions.

5. Assign the client to ask a question of a teacher, school 
Instructions to the clinician

Page 2

personnel, friend, or parent which uses the $/ 1 /$ sound.

6. Assign client to make a collage of $/ 1 /$ pictures, practicing the $/ 1 /$ sound as he is making it. When finished, he should return to the clinician and talk about them.

If you have any questions at any time, please call me at 245-3648 in the evenings. See you in five weeks!

Michelle Tremblay, investigator

Portland State University 


\section{APPENDIX E}

\section{CARRYOVER PROGRAM II}

Instructions to the clinician:

This is a five week carryover program. The client's progress will determine how rapidly you move through the program, so you may not complete all of the steps in five weeks. Each of the steps are to be followed in their entirety in the specified sequence. If the client does not meet criterion for a specified step, you must administer a branch step. The branch steps are provided on a separate chart. The client must then pass criterion for the branch step before advancing again to the step which he previously failed. For example, if your client produces $/ 1 / 80 \%$ in step 3 you would then administer Branch Step $C$, as indicated. When criterion for this branch step is met by the client, you would then readminister Step 3 .

Stimulus questions are provided as suggestions for the clinician and school personnel to use while talking to the client. Tracking forms are also provided to record the cllent's correct and incorrect /1/ productions. These forms are to be used by yourself and the school personnel as indicated in the steps of this program. You will instruct each of the individuals how to use the form. They are to return the form to you when the step is completed. A master record form is also provided for you to record the date, step number or branch step, percentage of pass or failure and the next step or branch 
Instructions to the clinician

Page 2

step to be administered. Please retain all records of this program.

If you have any questions at any time, please call me at

245-3648 in the evenings. See you in five weeks!

Michelle Tremblay, investigator

Portland State University 


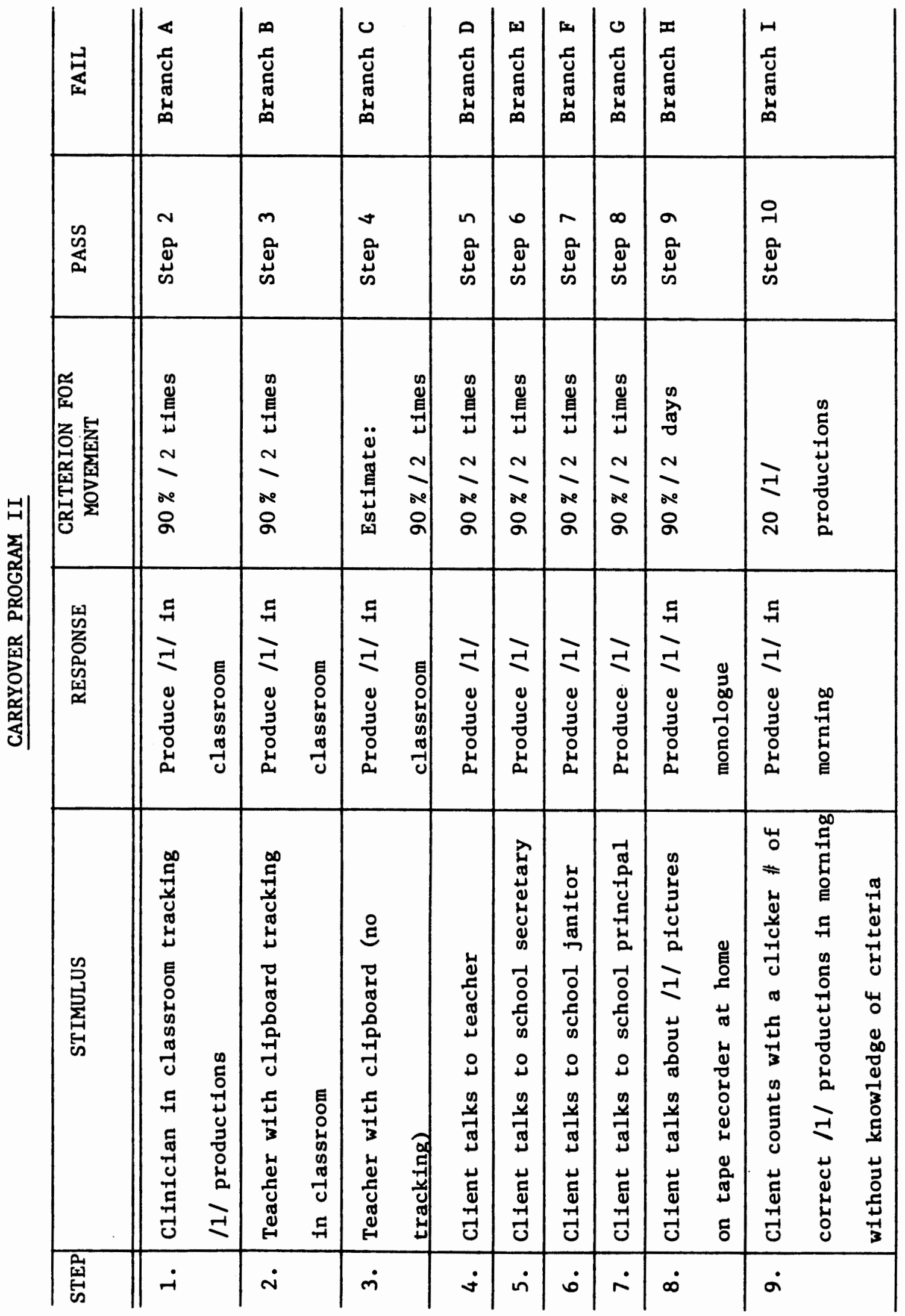




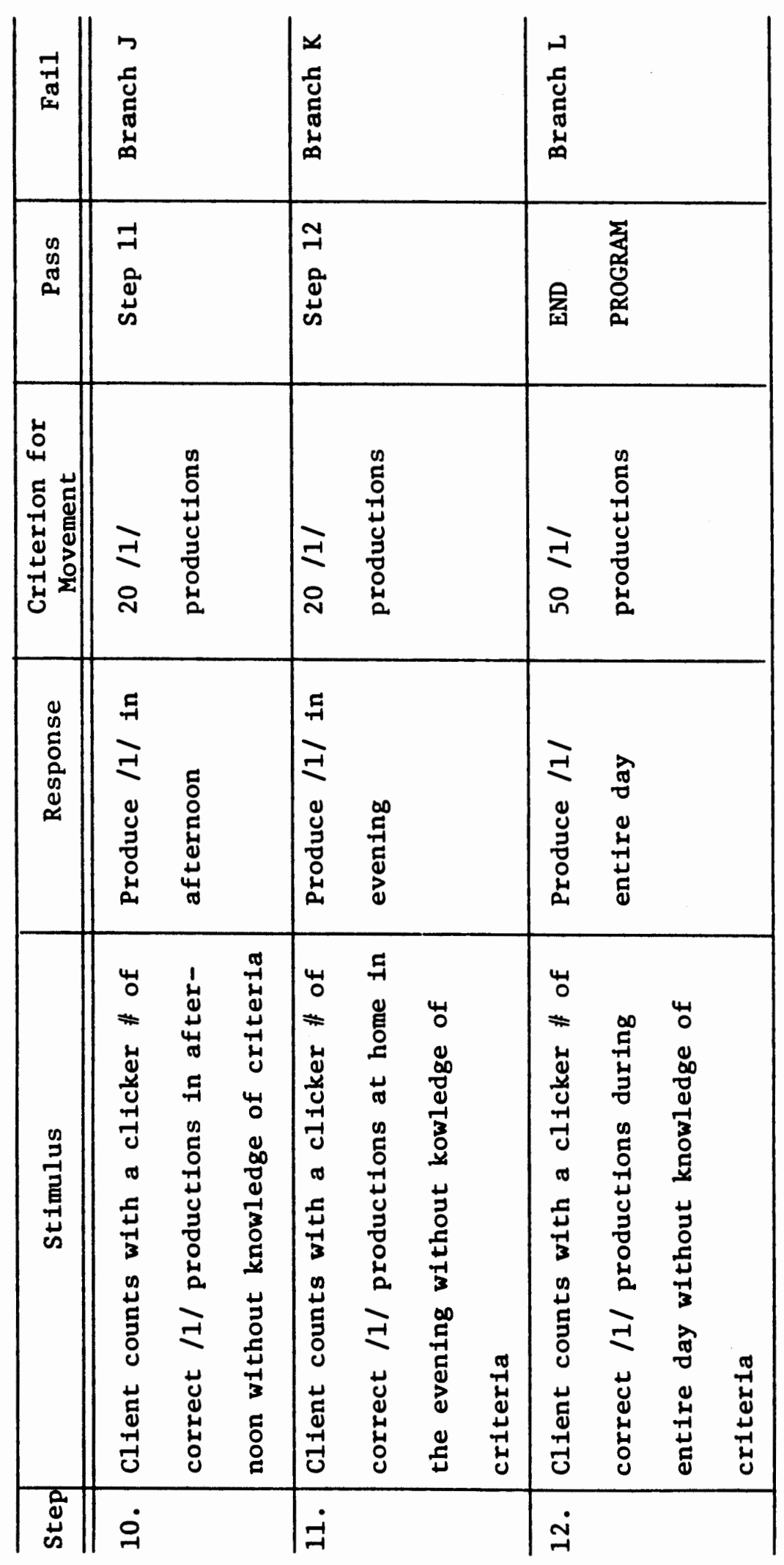




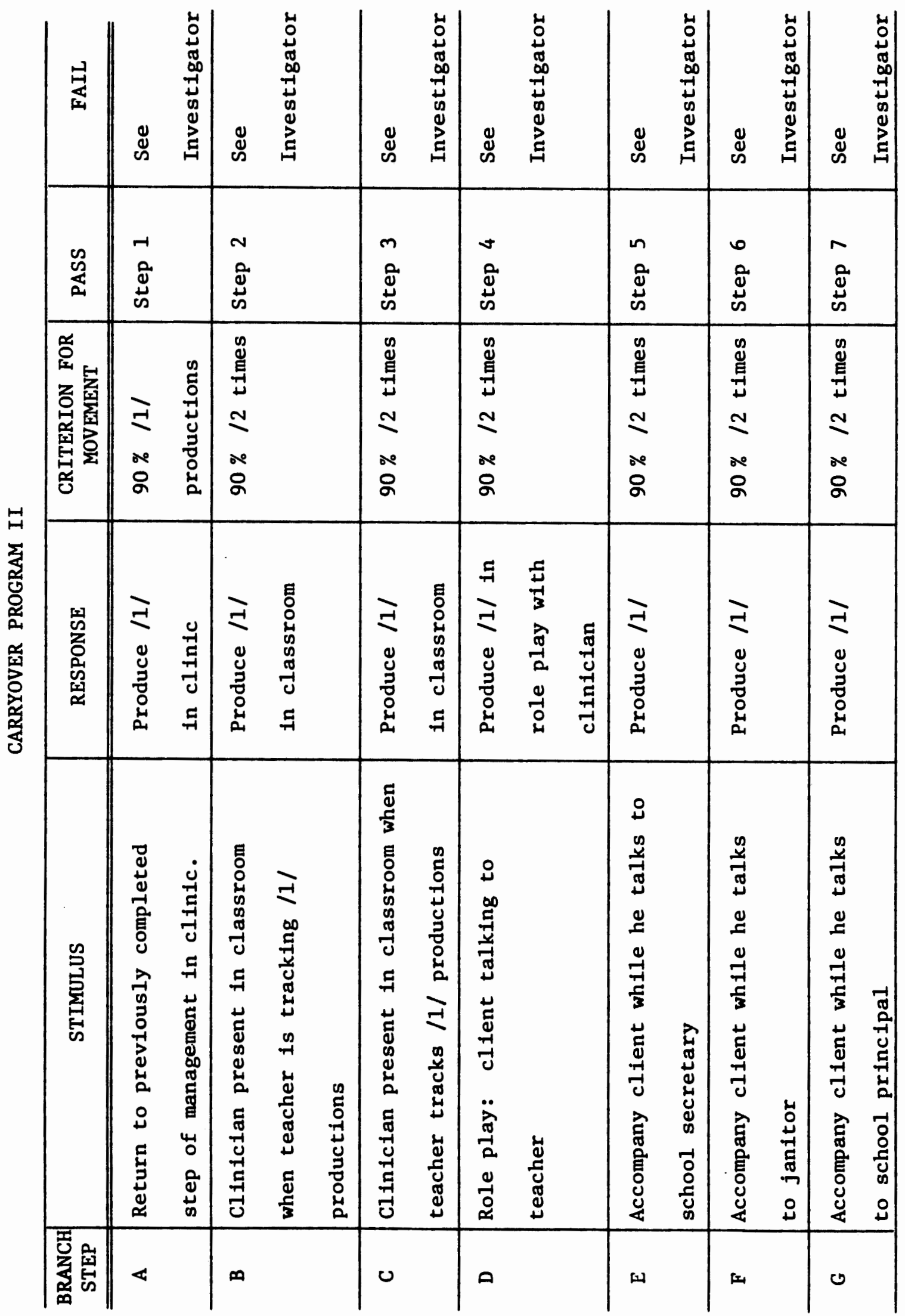




\begin{tabular}{|c|c|c|c|c|c|c|c|c|c|c|c|c|}
\hline $\begin{array}{l}7 \\
7 \\
\infty \\
\infty\end{array}$ & $\stackrel{\mathscr{\Perp}}{\mathscr{\Perp}}$ & 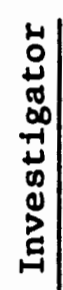 & $\stackrel{\mathscr{D}}{\mathscr{D}}$ & 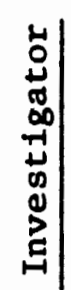 & $\stackrel{0}{\infty}$ & 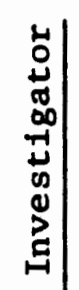 & $\underset{\mathscr{D}}{\mathscr{D}}$ & 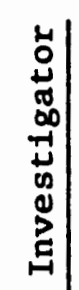 & $\stackrel{\Xi}{\mathscr{2}}$ & 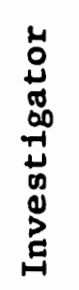 & & \\
\hline $\begin{array}{c}0 \\
0 \\
0 \\
0 \\
0\end{array}$ & 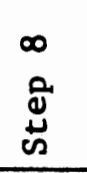 & & $\begin{array}{l}a \\
0 \\
0 \\
\Delta \\
\text { s }\end{array}$ & & 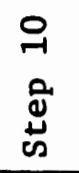 & & $\begin{array}{l}\exists \\
\Rightarrow \\
\stackrel{0}{D} \\
\stackrel{\Delta}{\infty}\end{array}$ & & 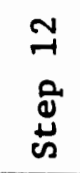 & & & \\
\hline 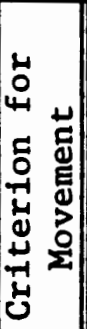 & 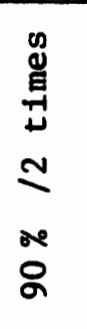 & & 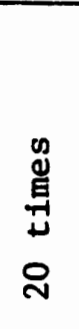 & & 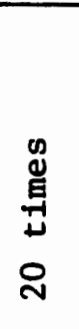 & & 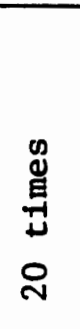 & & 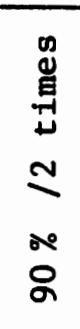 & 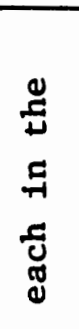 & 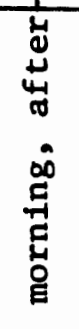 & 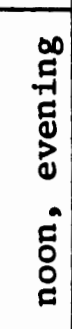 \\
\hline $\begin{array}{l}0 \\
0 \\
0 \\
0 \\
0 \\
0 \\
\tilde{d} \\
\tilde{\alpha}\end{array}$ & 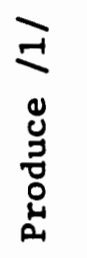 & & 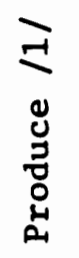 & & 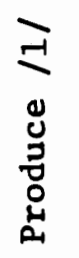 & & 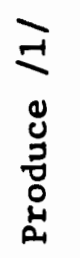 & & 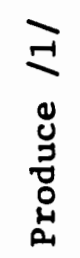 & & & \\
\hline 尝 & 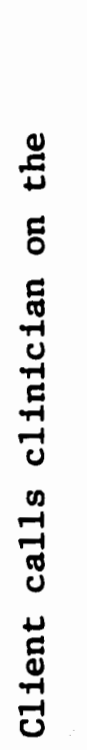 & 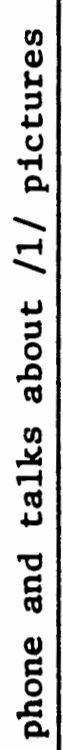 & 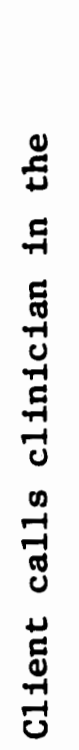 & 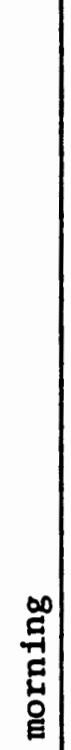 & 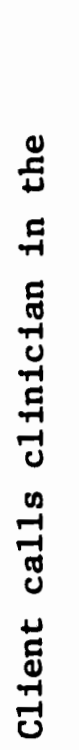 & 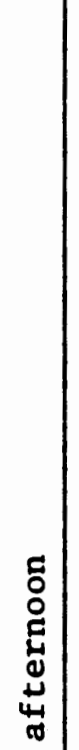 & 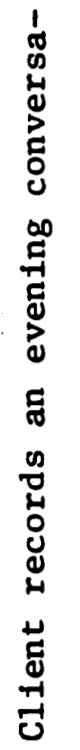 & 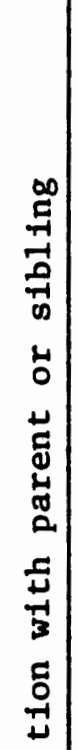 & 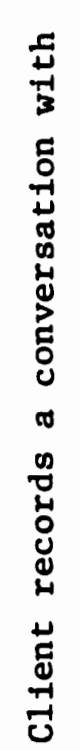 & 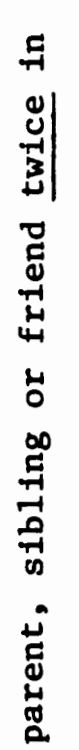 & 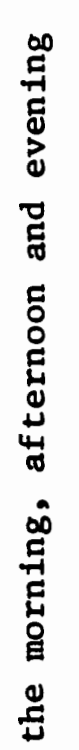 & 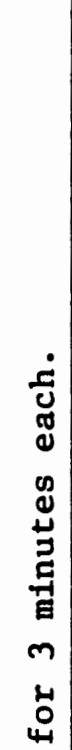 \\
\hline $\mid$ & $z$ & & $H$ & & 7 & & $\forall$ & & $\omega$ & & & \\
\hline
\end{tabular}


CARRYOVER PROGRAM II

Master Record Form

NAME

Age

DATE PROGRAM STARTED

DATE PROGRAM ENDED

CLINICIAN'S NAME

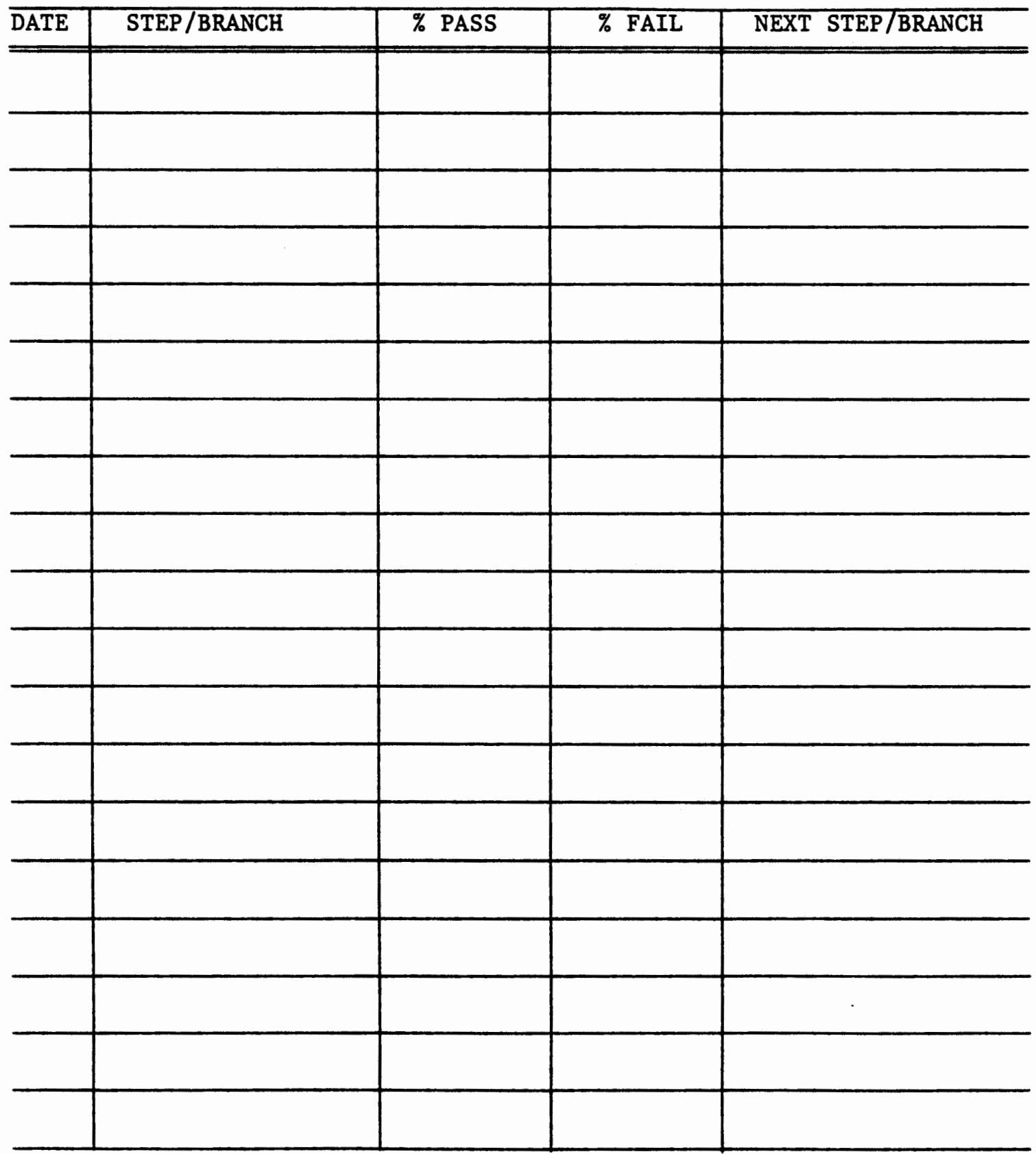


CARRYOVER PROGRAM II

Tracking Form

Client's Name

Date

Step or Branch

Tracker's Name

$X=\operatorname{correct} / 1 /$ production $0=$ incorrect $/ 1 /$ production

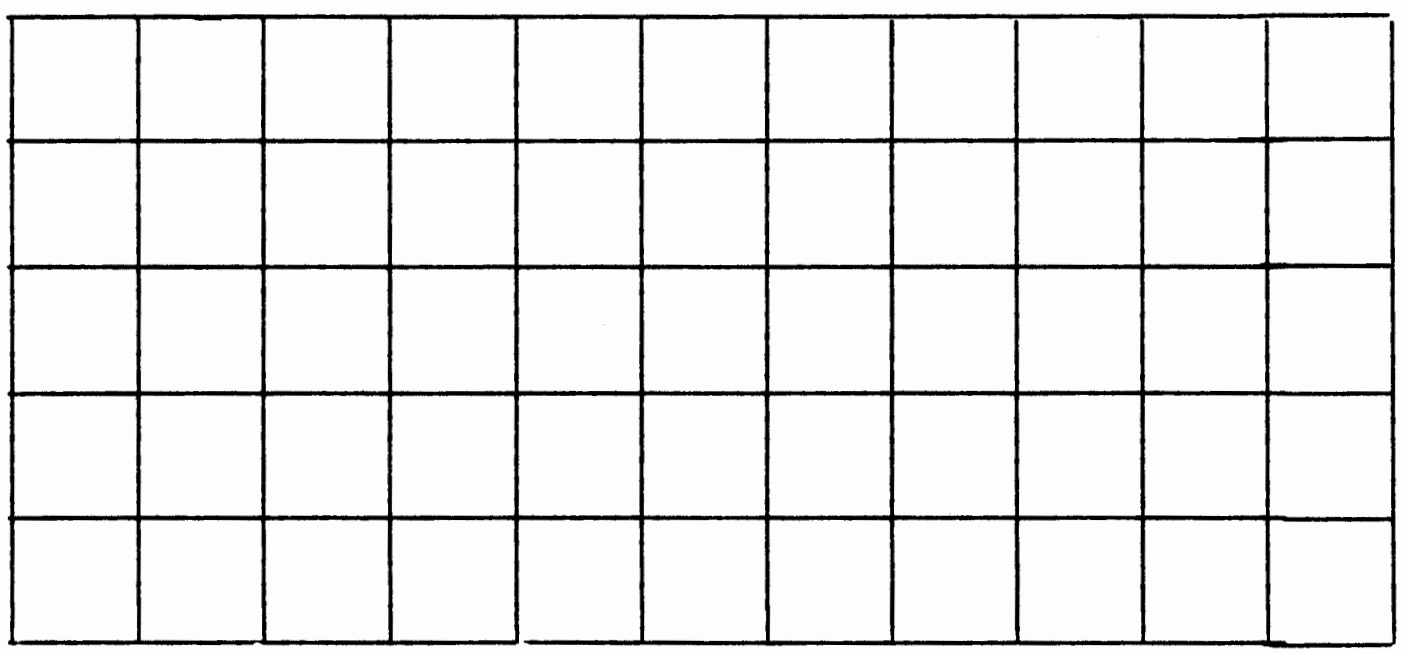

To be completed by the clinician:

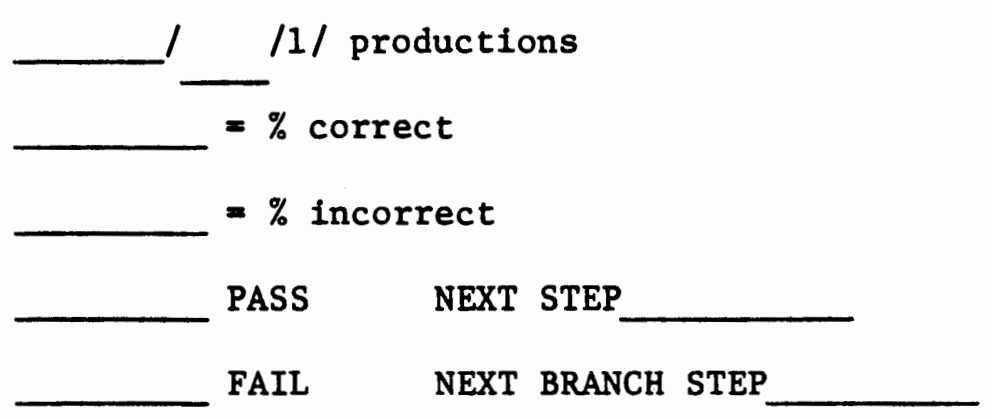




\section{CARRYOVER PROGRAM II \\ Possible Stimulus Questions}

The following are possible stimulus questions which you may give to the teacher, school secretary, janitor, and school principal to help in eliciting the /1/ phoneme in conversation with the client. These are only suggestions. Other topics which will elicit /1/ may be used.

How do you make lemonade?

How do you tie your shoe?

How do you play leap-frog?

What have you learned today?

What is a leprechaun?

Who do you write letters to?

What grows in a garden?

How do you make a salad?

What do you have for lunch?

How do you use sunglasses?

What is a thunderstorm like?

What are some things that grow on trees?

How do you do laundry?

What do you do when you are lost?

What do you use a lock for?

How does a lamp work?

What is a lightbulb for?
How do you cut your grass?

How are a flashlight and lamp alike?

How are a flashlight and lamp

$$
\text { different? }
$$

How do you find a book to read at school?

What could you use a rake for?

What happens when a volcano erupts?

What are your ears for?

What is a litterbug?

How do you draw a line?

What do you use a ladder for? 


\section{APPENDIX F}

\section{Clinician Questionnaire}

CIInician's Name

Dear Clinician:

Please complete the following questions. If you need more room feel free to use the back of this page and if you have any questions, please call me.

1. How long has your client been seen for speech management?

2. What sound(s) have you been working on with him/her?

3. Describe the approach you used for intervention prior to the carryover phase of management.

4. How did you involve the child in your management program (1.e. how responsible was he for his own program)?

5. How many years have you been working as a speech-language clinician in the public schools?

6. How many schools are you presently serving?

7. What is the size of your caseload? 
APPENDIX G

Client Case History

Name Birthdate Sex: $M \quad F$

Address Phone School Grade

Father's Name Mother's Name

DEVELOPMENTAL LANDMARKS

Used words Running Dressed self

Used sentences Sat alone Handedness

Walked alone Fed self Other

MEDICAL DATA - - Note age and/or information

Tonsils

Adenoids

Glandular problems

Weight problems

Encephalitis

Meningitis

Vision

Hearing

Dental

Birth problem

Lives with: Father: Mother: Step-father: Step-mother: Other: Father's occupation Mother's occupation

Others in household and student's position in family: 
Do you see any special problems at home or at school?

How does your child feel about his/her speech?

What are your concerns about his/her speech?

How does your child get along with his/her brothers and sisters?

Has your child been seen or examined at any of the following agencies? University of Oregon Medical School Child Guidance

Portland State University Welfare Portland Speech \& Hearing Clinic Other Agencies:

If there is not enough room to complete any part of this questionnaire, please use the back of the page. 